\title{
On Interactive Teaching Model of Translation Course Based on Wechat
}

\author{
Wang $\operatorname{Lin}^{1,2}$ \\ ${ }^{1}$ School of Foreign Languages and Literature, Wuhan University, Wuhan, China; \\ ${ }^{2}$ School of Foreign Languages, Leshan Normal University, Leshan, China \\ Correspondence: Wang Lin, School of Foreign Languages and Literature, Wuhan University, Wuhan, China; \\ School of Foreign Languages, Leshan Normal University, Leshan, China. Tel: 13880484919. E-mail: \\ w_lin832@163.com
}

Received: January 3, 2017 Accepted: February 1, 2017 Online Published: February 3, 2017

doi: 10.5539/elt.v10n3p21 URL: http://doi.org/10.5539/elt.v10n3p21

\begin{abstract}
Constructivism is a theory related to knowledge and learning, focusing on learners' subjective initiative, based on which the interactive approach has been proved to play a crucial role in language learning. Accordingly, the interactive approach can also be applied to translation teaching since translation itself is a bilingual transformational and communicative act. For a long period of time, there are a few universities in China having made use of network for translation teaching, but it is a pity that the most popular communicative software Wechat has not been attached importance to. This paper aims to elaborate the problems in current translation teaching and construct a new model for translation teaching through Wechat so as to further improve students' subjective initiative and the teaching efficiency.
\end{abstract}

Keywords: interactive teaching, translation teaching, Wechat

\section{Introduction}

Since 2006 Ministry of Education of China set up the major of translation at the undergraduate level, 215 universities or colleges all over the country have been authorized to launch translation major for undergraduates by the end of 2016. Different from English major, the major of translation owns its distinctive components such as training goal, teaching requirements, orientation and curriculum assignments. However, the translation teaching of this major still follow the traditional teacher-oriented pattern in some universities, and it is lacking in adequate interaction and fails to arouse students' subjective initiative. With the development of science and technology, the internet has been applied to translation teaching, which can function effectively in interactive teaching and definitely brings freshness to translation teaching.

\section{Literature Review}

In recent years, there are a few scholars having done research on translation teaching via the internet tool. Some scholars study the interactive teaching of translation from the perspective of internet (Duan, 2009; Yin 2006; Yu, 2014); some scholars study it from the perspective of computer-aided instruction (Ding, 2010) and some scholars study it from the perspective of blog and forum (Wan, 2012; Peng \& Li, 2011). Research mentioned above demonstrates huge effects on interactive teaching of translation from the internet. However, the above means inevitably have some limitations such as imbalance of resources that various users can enjoy, weakness of instantaneity, difficulty in operation and so on. Meanwhile, the rise of Wechat provides a new opportunity and it can integrate features of the precious means with its own new advantage, thus it is quite feasible to apply Wechat to the interactive teaching of translation. At present, research on translation teaching through Wechat is quite few. As far as the author has investigated, Wangli (2015) and Su Xiuyun (2015) have written papers about Wechat in translation teaching, but the former mainly focuses on the translation teaching at the level of university without talking about students(translators of the task) and the marketing (translation companies) while the latter fails to provide specific procedures. According the author, Wechat, as a newly developing instant communicative tool, can definitely exert positive effects on translation teaching in the classroom and beyond.

\section{Constructivism and the Interactive Teaching of Translation Course}

Constructivism, proposed by J.Piaget, is a theory about learning, which focuses on learners' subjective initiative. 
According to constructivism, learning is a process in which learners construct new understandings within the interaction of a certain social culture. Based on constructivism, interactive approach comes into being in language teaching and learning.

Interactive teaching arose in the $70 \mathrm{~s}$ of $20^{\text {th }}$ century, and it developed further later. According to interactive teaching, teachers and students exchange ideas towards some certain topic with each other in an equal way by means of various teaching platforms.

As requested by interactive teaching, the teacher is no longer the only dominant in class but a coordinator and advisor. In class, students act as the leading role, who, with the help of their teachers and of resources in class and beyond, exert the subjective initiative and the autonomy the utmost and actively discover problems, analyze problems, solve problems and acquire knowledge and experience in the end.

According to interactive teaching, there should be mutual communication, mutual learning and mutual inspiration between teachers and students on the one hand, and there should be mutual communication among students on the other hand. Additionally, students' interaction with the society, the market and the industry is also indispensible.

It is a few years since the interactive teaching has been introduced into translation course and its positive effects on translation teaching have been proved as well. Accordingly, translation, as a transformative and communicative act between at least two languages, badly needs interaction. Thus, translation teaching must be put into interaction rather than the pattern of teacher-centered. In fact, students, the center of teaching, should be the principal part of translation teaching, the active constructors of translation strategies and would-be professional translators. The translation teaching is a process, in which students solve various problems in translation through observation, discovery, analysis, discussion and practice under their teachers' guide. In this process, students' initiative, independence and enthusiasm will be greatly motivated while their dependence and laziness will be proportionally reduced.

\section{The Current Situation of Translation Teaching}

In view of the requirement for students' certain language capacity and other related knowledge, the translation curriculum is often arranged within the third year for undergraduate education of translation major by most departments of translation or colleges of translation and interpretation. Although it is a long period for the development of translation teaching, there are still some following problems.

Firstly, the teaching pattern still follows the traditional way. In a few universities or colleges, the translation teaching is teacher-centered without adequate participation of students. The basic model is the teacher's lecture on translation skills or strategies, and then teacher's demonstration by examples, and then students' practice by exercise and homework and finally the teacher's comments. In this teaching model, the teacher always plays a role of dominator and feeds anything to students, and accordingly the students take notes passively without adequate thinking and discussing, which is harmful for translation practice. In addition, a large amount of homework may lead to the teacher's inadequate and ineffective comments or even a date alone instead of comments.

Secondly, the evaluation method is onefold. As for homework, the teacher's comment accounts for most with few occasions of mutual evaluation among students. Additionally, some teachers hand out reference version in order to make students correct all by themselves. In fact, it is inappropriate to evaluate translation without discussion and exchange.

Thirdly, the link between the class and the industry or the market is insufficient, which is harmful for cultivating practical talents in the translation field.

\section{The Interactive Advantage of Wechat}

Wechat is a free and instant messaging software launched by Tencent(a leading provider of Internet value added services in China) in 2001, by which users can send and receive instant text information, voice messages, short videos and pictures though the Internet in the way of across-communication operator, across-operating system and across-country. Additionally, it has many useful plug-ins such as "shake", "Scan QR Code", "Message in a Bottle", "Moments", "Subscription Accounts" and "Group Chat". There had been 500000000 users across more than 200 countries by the end of 2015. Compared with other Internet platforms (BBS, QQ and Blog), Wechat takes absolute advantage in terms of instantaneity and operational convenience and it collects the advantages of the software mentioned above.

In terms of interactive teaching, Wechat has the following advantages. 
Firstly, Wechat is of obvious instantaneity, by which the teacher and students can communicate with each other about teaching and learning free from the restriction of time and space.

Secondly, Wechat is of diverse ways of discussion. Discussion can be realized between the teacher and students, among students and on and off campus through private message, group chat, moments, subscription accounts, short video and voice message. For each student, Wechat can provide the same opportunity for participation, thus it is good for someone to overcome timidity.

Thirdly, group chat of Wechat is of certain equality. There is no prominent contrast of different statuses between the teacher and students, or there is no specific administrator with certain privilege like that in the group chat of QQ or BBS. Thus, students are free to communicate with their teacher or their classmates.

Fourthly, various plug-ins of Wechat, which are not contained in other Internet platforms, can definitely provide better service for teaching and learning.

To sum up, Wechat's advantages in interaction make its application to translation teaching feasible.

\section{The Interactive Teaching Model of Translation Course Based on Wechat}

\subsection{Main Modules and Their Functions of Wechat's Application to Translation Teaching}

Table 1. Wechat's Functions in Translation Teaching

\begin{tabular}{ll}
\hline Main Modules & Functions \\
\hline Private Message(Text) & $\begin{array}{l}\text { communication within the teacher and students } \\
\text { communication within the teacher and students } \\
\text { Private Message(Voice) }\end{array}$ \\
$\begin{array}{l}\text { communication within a class or a team } \\
\text { exhibition of versions and communication with the } \\
\text { industry and market }\end{array}$ \\
Subscription Accounts & to issue tasks, to show versions or to comment \\
Moments & to collect and issue classics \\
Favorites & discussion by class, team or unit \\
Audio and Video & to deliver a message to many recipients at once \\
Broadcast Messages & to get related information quickly \\
Shake \& Scan & to function quickly \\
Wechat in Windows &
\end{tabular}

\subsection{Interaction before Class}

Before class, the teacher can publish the syllabus, teaching objectives and other information through Wechat in order to make it known to students. Thus communication about teaching content can be done between the teacher and his students, which is good for the realization of teaching task and the satisfaction of students' taste. In this way of Wechat communication the course by the two parties, the teacher- led and students-centered teaching model can be effectively guaranteed. Having confirmed the content for each course, the teacher can publish questions, topics and related materials through subscription accounts, group chat or moments.

\subsection{Interaction during Class}

The translation course is full of practice, thus the exercise or quiz is the norm. At this moment, Wechat can play an important role. In the multi-media classroom, the teacher can assign some translation task and require his students to finish it within a certain period of time through Wechat in Windows. Because of its convenience for typewriting on the keyboard of computer and comparing the source text and the target text on the screen, Wechat in Windows can promote students to finish their tasks efficiently in a competitive atmosphere. Finally, each version can be clearly presented in group chat for discussion and evaluation. Compared with the traditional way of practice by blackboard or projector, translation practice by immediate Wechat can bring the equal communication to each student as much as possible on one hand, and can make evaluation more efficiently on the other hand. 
Translation learning demands a lot of practices, and it is better to say that translation is a practicing course rather than a theory study. Therefore, work after class is a very important part, in which the interaction is of great significance.

First of all, interactive homework evaluation can be conducted through Wechat. For translation teachers, homework checking is a quite tiring job. It is both time-consuming and labor-intensive for them to carefully correct dozens of translation homework. In order to save time and energy, some teachers even finish checking by simply sketching and marking, and then adding the date. For students, they can only see their own revised translation version or even the reference one. Via the Wechat platform, homework checking can be carried out in an interactive way, in which the teacher and all his students can be involved. In this way, the workload of the teacher can be greatly reduced so that he can concentrate on dealing with key problems in translation homework. Additionally, students' enthusiasm and initiative can be fully mobilized. Exposed to different translations, students can overcome their own weak points by learning from each other's strong points. More importantly, students will not depend on reference translations, exploring their own translation characteristics and style bravely.

Secondly, interactive Q \& A can be conducted through Wechat after class. For students majoring in translation, it is far from enough to learn from their textbooks only. On the contrary, they should widely read a large number of materials within translation major and beyond after class. When students encounter problems, they can submit them to the Wechat platform and discuss them with the teacher and other classmates. In this way, students will benefit a lot.

Thirdly, interactive tests can be conducted through Wechat after class. The whole class, a group, or certain members can do the regular or irregular translation quiz by Wechat's group chat or moments. This kind of test owns intensive participation, excellent instantaneity and a little limitation, which extremely facilitates the interaction between the teacher and his students, and among students themselves.

Finally, students can get access to the translation industry and the translation market through Wechat. With the arrangement of the college or the teacher, students can regularly interact with the local foreign affairs department, translation associations, translation companies and training institutions for translators through Wechat. With the guidance of professional translators through Wechat, students can have an in-depth understanding of the translation industry and get some extra-curricular knowledge, which will lay a solid foundation for their practice and employment in the future. In addition, students are allowed to learn and appreciate excellent translation works and various types of translations for practical texts via the platform of Wechat.

Students' role as the center in the translation teaching can be effectively guaranteed through Wechat, as shown below:

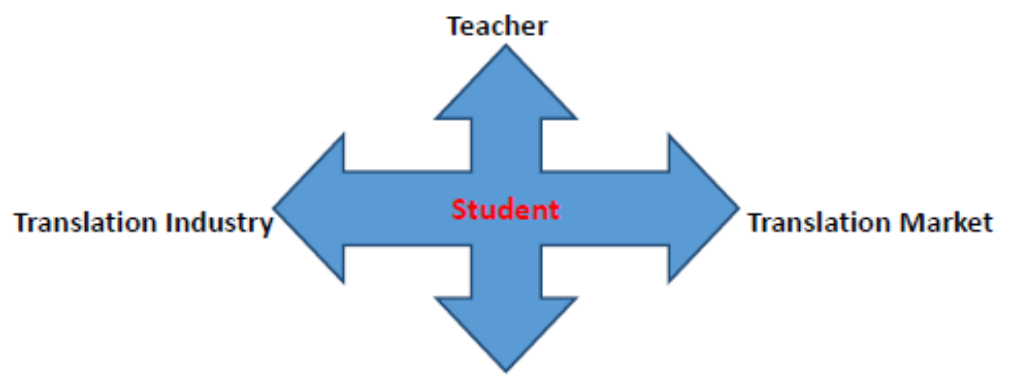

Other Students

Figure 1.Students'role in Wechat-based interactive teaching of translation

\section{Conclusion}

To sum up, the Wechat-based interactive teaching model of translation course can solve many problems in the traditional teaching model, especially playing a critical role in the translation major that urgently calls for practice and application. The new teaching theories such as constructivism, task-based teaching and situational teaching, can really be adopted in the teaching process. The role of the teacher as an organizer and coordinator inside and outside the classroom are more prominent and so is students' role as the host in the center of the class, 
which effectively helps the students improve their translation skills.

\section{References}

Ding, Y. (2010). Practice on computer aided interactive translation teaching model. Journal of Changsha Telecommunications and Technology Vocational College, 2, 108-111.

Duan, Z. (2009). An empirical study on campus Internet-based peer review and interactive translation training. Chinese Translators Journal, 3, 44-49.

Peng, Z., \& Li, Y. (2011). A study of interactive translating teaching model based on BBS. Journal of Jiangxi Normal University (Social Sciences), 5, 136-139.

Su, X., \& Cui, S. (2015). The function of Wechat in the interactive translation teaching. Asia-Pacific Education, $10,291$.

Wang, L., \& Dai, J. (2015). The construction and application of the Wechat-based mobile interactive translation teaching model. Technology Enhanced Foreign Language Education, 2, 35-41.

Wan, Z. (2012). An exploration of interactive translation teaching model based on multi-media and blog. E-Education Research, 4, 95-98.

Yin, P. (2006). The new type collaborative translation teaching under the situation of network. Journal of Anhui University of Technology (Social Sciences), 6, 81-82.

$\mathrm{Yu}, \mathrm{X}$. (2014). Interactive translation teaching based on the network. Journal of North China Institute of Science and Technology, 7, 100-103.

\section{Copyrights}

Copyright for this article is retained by the author(s), with first publication rights granted to the journal.

This is an open-access article distributed under the terms and conditions of the Creative Commons Attribution license (http://creativecommons.org/licenses/by/4.0/). 